\title{
Challenges to Nursing Regulation During the Pandemic: A Case Study
}

\author{
Lori Scheidt, MBA-HCM
}

The COVID-19 pandemic put an unprecedented strain on the nursing workforce. In response, many states issued executive orders waiving licensure requirements for their state if nurses have a license in good standing in another state. However, such efforts were not without risk. For example, a nurse who was working in a state under an executive order was terminated by the employer after the nurse was found diverting controlled substances and diluting vials of controlled substances with normal saline. This case study highlights the importance of the authority provisions granted in the Nurse Licensure Compact and the risk to public protection that can potentially result when executive orders waive the requirement for an in-state nursing license.

Keywords: Nurse Licensure Compact, drug diversion, executive orders, discipline, COVID-19 pandemic

$\mathrm{T}$ The Nurse Licensure Compact (NLC) was developed by the National Council of State Boards of Nursing in 1999 to reduce barriers for nurses who wish to practice in different states (Evans, 2015). In the early days of the COVID-19 pandemic, the state of New York-which is not a member of the NLC_-issued executive order 202.5, which allowed registered nurses, licensed practical nurses, and nurse practitioners who were licensed and in good standing in any U.S. state to practice in New York State without civil or criminal penalty related to lack of licensure (N.Y. Exec. Order No. 202.5, 2020). The order was issued on March 18, 2020, and was to remain in place until June 25, 2021.

\section{Facts of the Case}

Nurse A was licensed as a registered nurse in Missouri, which is part of the NLC. Although New York is not an NLC state, per New York's executive order, Nurse A was allowed to practice at a hospital in New York, New York. The facts of the case brought against Nurse A show that she diverted diphenhydramine (Benadryl) injections and propofol for her own use. Nurse A admitted that she also diverted fentanyl and hydromorphone for a use other than what it was originally intended. Nurse A tampered with fentanyl vials by removing the original medication from the vial with a syringe and then diluting said medication with normal saline. Nurse A wrote a statement dated April 24, 2020, admitting to intentionally taking Benadryl and propofol for her own personal use and also knowingly diverting, approximately 20 times, narcotic medications (fentanyl and hydromorphone).

\section{Investigation, Disciplinary Hearing, and Board of Nursing Decision}

Nurse A's employer in New York initially filed a complaint with the nursing board in New York in response to her conduct. When the New York nursing board declined to investigate, her employer notified the Missouri State Board of Nursing (Board). The Board investigated the case as a priority and ultimately filed a complaint against Nurse A with the Administrative Hearing Commission on November 10, 2020. The Administrative Hearing Commissionwhich conducts hearings and makes findings of fact and conclusions of law when a nurse may be disciplined by a board-issued an order April 1, 2021, finding that the Board had cause to take disciplinary action against Nurse A's license. The Board convened a hearing on May 26, 2021, to determine what discipline, if any, should be imposed on Nurse A's license. Ultimately, the Board decided to revoke Nurse A's registered nurse license on July 6, 2021.

In the analysis section of the Order, the Board indicated:

An essential function of a registered nurse is to properly and lawfully account for, administer, and document medications. Respondent has not demonstrated she can be trusted to do so. The evidence before the Board demonstrates that Respondent failed to perform an essential function of her job regarding medications and ingested medications, including narcotics, for which she did not have a prescription, all of which could endanger the public bealth. In ber effort to divert narcotics, Respondent removed medication from their vials and replaced the missing narcotics with Normal Saline. This unethical and unsafe practice not only endangers the bealth of patients but could result in patient suffering as their pain goes untreated. The public expects nurses to not possess, divert, or abuse narcotics or other medications and Respondent has eroded those 
expectations. Nursing is a bighly responsible profession requiring trustwortbiness and integrity of its members. Respondent's actions were explicitly contrary to these nursing standards (Missouri State Board of Nursing, 2021).

The Administrative Hearing Commission concluded the Board has cause to take disciplinary action against the Respondent's nursing license based on a number of Missouri Revised Statutes (The Nursing Practice Act, 2013/2018):

- "Use or unlawful possession of any controlled substance, as defined in chapter 195, by the federal government, or by the department of health and senior services by regulation, regardless of impairment" (§ 335.066.2(1)).

- "Misconduct, fraud, misrepresentation, dishonesty, unethical conduct, and unprofessional conduct in the performance of the functions and duties of [a nurse]" ( $\$ 335.066 .2(6))$.

- "Failure ... to cooperate with the Board" during its investigation of the matter $(\S 335.066 .2(6)(\mathrm{h}))$.

- "A departure from or failure to conform to nursing standards" $(\S 335.066 .2(6)(\mathrm{n}))$.

- "Failing to assess, accurately document, or report the status of a patient, resident, or client or falsely assessing, documenting, or reporting the status of a patient, resident, or client" $(\S 335.066 .2(6)(\mathrm{q}))$.

- "Violation of any professional trust or confidence" (§ 335.066.2(13)).

- "Violation of the drug laws or rules and regulations of this state, any other state or the federal government" (§ 335.066.2(15)).

- "A pattern of personal use or consumption of any controlled substance or any substance which requires a prescription unless it is prescribed, dispensed, or administered by a provider who is authorized by law to do so or a pattern of abuse of any prescription medication" (\$ 335.066.2(20)).

- "Diversion or attempting to divert any medication, controlled substance, or medical supplies" (§ 335.066.2(25)).

- "Any conduct that constitutes a serious danger to the health, safety, or welfare of a patient or the public" (§ 335.066.2(28)).

Some states, including Missouri, have a mandatory reporting law. Missouri's mandatory reporting law requires employers to report any disciplinary action against a healthcare professional to the appropriate healthcare professional licensing authority (Mandatory Reporting, 1986/2008). Because the organization at which Nurse A's infraction took place was in New York, it had no duty to report her conduct to Missouri). Had the New York employer not reported this conduct to Missouri, an investigation would not have been conducted.

Furthermore, because New York is not a member of the NLC, New York had no authority to investigate this case. If New York had been a member of the NLC, New York would have had to give this case the same priority and effect as a New York licensee case and could have taken action against this nurse's privilege to practice in its jurisdiction. Ultimately, the New York regulatory authority declined to investigate due to lack of jurisdiction. This nurse was free to practice without restriction, thus leaving the public at potential risk of harm.

\section{Discussion}

Boards of nursing exist to protect the public and operate under state laws that delineate their power and duties. If a board of nursing is not a member of the NLC, that board only has authority to investigate and discipline those individuals licensed by their respective board (National Council of State Boards of Nursing, 2021).

Unlike these states outside of the NLC, states that are NLC members have additional authorities. The NLC allows a multistate license to be issued by the nurse's primary state of residence (home state). That multistate license is recognized by all other NLC states (remote states) under a multistate licensure privilege. Article V of the NLC authorizes a remote state to take action against the nurse's multistate licensure privilege-including issuance of subpoenas for hearings and investigations-requiring complaints to be given the same priority and effect as a complaint against a home state license, and prompt reporting of any appropriate action to the Nursys database. Finally, Article V allows a remote state to issue cease-anddesist orders or impose an encumbrance on a nurse's authority to practice within that remote state (National Council of State Boards of Nursing, n.d.).

The COVID-19 pandemic placed tremendous pressure on healthcare resources. In response, governors in many states issued executive orders that allowed nurses to practice with a valid nurse license issued by another state in order to give healthcare facilities access to more nurses. Resolving a complaint when a nurse practiced under an executive order presented unique challenges, such as the timely investigation of the conduct, the ability to issue subpoenas, and the ability to take prompt action and report that action. This case against Nurse A illustrates these challenges.

\section{Conclusion}

The public continues to be protected when a nurse practices in another state with a state-issued license because the state is vested with authority to investigate complaints and take action, when appropriate. The public is also protected if the nurse holds an NLC multistate license and practices in another NLC state. This protection results from the provisions in the NLC that allow for timely investigation and action against a multistate license privilege. If the nurse does not have a license or privilege to practice in the state of practice, there is no obligation for the state of practice to investigate a complaint and take disciplinary action, if appropriate. In order to preserve the state of practice's public protection mandate or protect the public, the state may wish to consider waiving the licensure fee and issuing expediting authority to practice. 


\section{References}

Evans, S. (2015). The Nurse Licensure Compact: A historical perspective. Journal of Nursing Regulation, 6(3), 11-16. https://doi.org/10.1016/ S2155-8256(15)30778-X

Mandatory Reporting, Mo. Stat 383 § 383.133 (1986 \& rev. 2008). https://www.revisor.mo.gov/main/ViewChapter.aspx? chapter $=383$

Missouri State Board of Nursing v. Mandy Lafferty, Case Nos. 2020001486, 2020-000425 and 20-2980 (2021).

National Council of State Boards of Nursing. (n.d.). Nurse Licensure Compact (NLC). Retrieved September 28, 2021, from https://www. ncsbn.org/nurse-licensure-compact.htm/NLC_Final_050415.pdf

National Council of State Boards of Nursing. (2021, August). NCSBN model act. https://www.ncsbn.org/14_Model_Act_0914.pdf

The Nursing Practice Act, Mo. Stat. $335 \S 335.066$ (2013 \& rev. 2018). https://revisor.mo.gov/main/OneSection.aspx?section=335.066\&bid $=35888 \& \mathrm{hl}=$

N.Y. Exec. Order No. 202.5 (2020, March 18). https://www.governor.ny. gov/sites/default/files/atoms/files/EO_202_5.pdf

Lori Scheidt, MBA-HCM, is the Executive Director, Missouri State Board of Nursing, Division of Professional Registration, Missouri Department of Commerce \& Insurance, Jefferson City.

Conflicts of Interest: None. 